\title{
Aspiration, risk and risk feeding: A critique of the Royal College of Physicians guidance on care of people with eating and drinking difficulties
}

\author{
Shaun T. O’Keeffe ${ }^{\mathrm{a}, *}$, Aoife Murray ${ }^{\mathrm{b}}$, Paula Leslie ${ }^{\mathrm{c}}$, Lindsey Collins ${ }^{\mathrm{d}}$, Tracy Lazenby-Paterson ${ }^{\mathrm{e}}$, \\ Arlene McCurtin ${ }^{\mathrm{f}}$, Siofra Mulkerrin ${ }^{\mathrm{g}}$ and Alison Smith ${ }^{\mathrm{h}}$ \\ ${ }^{a}$ Department of Geriatric Medicine, Galway University Hospitals, Galway, Ireland \\ ${ }^{\mathrm{b}}$ School of Medicine, National University of Ireland Galway, Ireland \\ ${ }^{\mathrm{c}}$ Department of Speech and Language Therapy, Lancashire \& South Cumbria NHS Foundation \\ Trust Hospital \& Health Care, Preston, United Kingdom \\ ${ }^{\mathrm{d}}$ Centre for Applied Dementia Studies, Faculty of Health Studies, University of Bradford, Bradford, \\ United Kingdom \\ ${ }^{\mathrm{e}}$ NHS Lothian Community Learning Disability Service, Leith Community Treatment Centre, Edinburgh, \\ United Kingdom \\ ${ }^{\mathrm{f}}$ School of Allied Health, University of Limerick, Limerick, Ireland \\ $\mathrm{g}^{\mathrm{g}}$ Department of Speech and Language Therapy, Addenbrooke's Hospital, Cambridge, United Kingdom \\ ${ }^{\mathrm{h}}$ Pharmacy and Medicines Optimisation Team, Herts Valleys Clinical Commissioning Group, Hemel Hempstead, \\ United Kingdom
}

Received 30 June 2021

Accepted 2 September 2021

\begin{abstract}
The Royal College of Physicians has recently published guidance on supporting people with eating and drinking difficulties. Although much of the advice in the guidance is sensible and helpful, in this paper we argue that the recommendations regarding 'risk feeding' decisions are flawed. In particular, there is a failure to clearly identify the nature, frequency and severity of different risks. There is an undue emphasis on aspiration as a risk and as a potential cause of pneumonia, and the limited evidence base for many interventions to manage risk is not adequately acknowledged. There is an emphasis on multidisciplinary team decision making at the expense of individual professional responsibility. We conclude that this guidance regarding risk feeding supports an unduly defensive approach to oral intake and should not be adopted as a standard of medical practice.
\end{abstract}

Keywords: Dysphagia, aspiration, risk feeding, pneumonia, defensive medicine

\section{Introduction}

In recent years, many hospitals have developed

*Corresponding author: Prof. Shaun O'Keeffe, Department of Geriatric Medicine, Galway University Hospitals, Newcastle Rd, Galway, Ireland. E-mail: sokeeffeanc@gmail.com. 'risk feeding' policies for those 'who continue to eat and drink orally despite a perceived risk of choking or aspiration,' (Hansjee, 2018; NNUH, 2021; Som- 
merville et al., 2017). Different hospitals and writers have taken slightly different approaches and there has been no agreed policy or even consensus on terminology. The terminology and concepts behind risk feeding have been criticised (Murray et al., 2019).

A working party of the Royal College of Physicians (RCP) has recently published guidance on supporting people who have eating and drinking difficulties (RCP, 2021). Some aspects of this guidance are specific to Britain: there are references, for example, to the Mental Capacity Act 2005 (MCA), which is a statute in force in England and Wales. Nevertheless, the RCP guidance is very likely to prove influential outside England and Wales. The RCP is respected worldwide and plays a leading role in setting standards of medical practice. The guidance has been endorsed by, among other influential bodies, the British Dietetic Association, the British Geriatrics Society, the British Society of Gastroenterology, Dementia UK, the Malnutrition Task Force (Age UK) and the Royal College of Speech and Language Therapists.

Much of the advice in the guidance is informative and sensible and will be helpful for practitioners. In this paper, we examine the comments regarding risk feeding and, in particular, aspiration. We acknowledge the good intentions of the authors, and of proponents of risk feeding in general, and share the overall goal of promoting oral intake in those with dysphagia. However, we believe there are significant deficits in this document with regard to the risk feeding recommendations. (Quotations, unless otherwise specified, are from the specified sections of the RCP guidance).

\section{Summary of RCP guidance regarding risk feeding}

The basic premise of this guidance is that for those with eating and drinking difficulties, oral intake itself is an important cause of adverse outcomes and that alternative approaches, such as use of modified texture diets, a nil-by-mouth (NBM) status or clinically assisted nutrition and hydration (CANH), will greatly reduce those adverse outcomes. (If the adverse outcomes are due to dysphagia or to the conditions causing dysphagia, rather than to oral intake, or if there are no proven safer alternatives to maintaining hydration and nutrition, why bother having a policy?).

Some patients choose not to accept the recommended approach to receiving hydration and nutrition,
- usually made initially by Speech and Language Therapists (SLTs). The RCP guidance counsels in such cases that the patient's decision to eat and drink should be discussed in a multidisciplinary team (MDT) meeting and carefully documented and communicated to patients and relevant staff. A similar MDT discussion should occur if somebody is judged to lack capacity to make their own decision and if the 'best interests' - this being much more than purely 'medical best interests' - decision is made that he or she will eat and drink orally despite the potential risks. In some circumstances, seeking legal advice as to whether a court application is required is recommended in the policy especially if competing rights of carers are involved.

\section{The problem with 'risk' language}

The very language of used in risk feeding policies is problematic. To many people risk implies danger. 'Risk-anything' is not how healthcare (or other) decisions are reached (Murray et al., 2019). Any healthcare intervention has potential benefits and hazards which people consider so they can weigh up their options in the context of their preferences and goals and make their own decision on how to proceed.

The main risks of concern related to oral intake in the RCP guidance are 'unacceptable coughing' and choking or aspiration especially when these occur in someone eating and drinking in a way contrary to professional advice (RCP, 2021, pp. 24-26). However, the risk feeding section (RCP, 2021, pp. 25-26) refers throughout to generic 'risks' rather than specifying exactly what observation or event should trigger the various recommendations. This is unfortunate as these risks are very different, and a distinction between potential asphyxiation and aspiration is particularly important. Potential adverse outcomes when people adhere to professional recommendations do not receive equal weight or recognition as risks. These include poor nutrition and hydration due to modified texture diets and thickened liquids, pneumonia in those taking very thick fluids and an adverse impact on quality of life (O'Keeffe, 2018; Swan et al., 2015).

Risk is meaningless without reference to a specific adverse outcome, the likelihood it will occur and how severe the impact is for an individual. The RCP guidance does not comment on how great or real the risks must be before formal risk feeding meetings and decisions are required. Their definition of risk feeding refers to 'a perceived [our emphasis] risk of choking 
or aspiration' (RCP, 2021, pp. 24-26). This raises the question 'whose perception and is it justified?' since, as the guidance later acknowledges, misperceptions abound regarding simplistic links between aspiration and pneumonia in particular. One of the few empirical studies of risk feeding policies noted that for some patients 'that the risks giving rise to staff concerns may be "small or putative" (Sommerville et al., 2017). This raises the possibility of MDT meetings being convened whenever there is any perception that a patient might, for example, develop pneumonia that could be attributed to oral intake.

\section{Unacceptable coughing}

The sensation of food or fluid going down the wrong way is a deeply unpleasant one. We all experience this sensation when our intact protective cough reflex is activated. Thus, in itself, coughing is not a risk. People who eat and drink with difficulty will, for a particular diet at a particular time, decide whether their pleasure and relief outweigh their distressing symptoms. To whom is the coughing 'unacceptable'? As with any medical intervention this judgement should lie with the patient. The patient has the right to choose if a feature of their condition (coughing) is worth more than the side effects of any intervention (such as modified texture diets).

\section{Choking, asphyxiation and near-asphyxiation}

The terms choking and aspiration should not be conflated. Choking due to foreign body airway obstruction is a rightly-feared, life-threatening medical emergency. Every year, thousands of predominantly older people, often with neurological disease and poor dentition, die after choking on food (Elflein, 2021; ONS, 2018; Wu et al., 2015). Some modification of diet texture is important for those at highest risk for this outcome. Recommending that solid food is at least cut to manageable chunks for the individual seems reasonable, although there is little good evidence to guide practice (Steele et al., 2015). Can this always be prevented? It is true - if not very helpful - that someone who does not eat at all will never choke on food. The speed of eating and food textural attributes such as stickiness, hardness and shape may be as important as bolus size with respect to choking risk. A high proportion of fatal and near-fatal choking episodes in older people occur with semisolids including pureed consistencies, and interventions such as abdominal thrusts are less likely to be effective in such cases (Ekberg \& Feinberg, 1992).

\section{Aspiration and pneumonia}

Pneumonia is a common cause of illness and death in those with dysphagia. Dysphagia increases the risk of aspiration, or entry of foreign material into the airways. In general, those who aspirate more on instrumental assessments conducted by SLTs are more likely to develop severe pulmonary complications such as pneumonia (Steele \& Grace-Martin, 2017). It is argued that thickening fluids, which slows their flow rate, may reduce - but not eliminate - the risk of aspiration, and modified texture food may be easier to swallow for those with chewing problems (Wirth et al., 2016).

\subsection{Aspiration per se as a 'risk'?}

It is meaningless to consider aspiration in isolation as a risk without considering the nature, volume of the aspirated material and the frequency and chronicity of aspiration (Marik, 2011). Small-volume silent aspiration of clean material has no link with chest infections, and aspiration of no clinical consequence is increasingly identified in healthy older adults (Butler et al., 2014)

In contrast, a large-volume aspiration of upper gastrointestinal contents, for example due to enteral feeding, will often lead to pneumonitis. Continual aspiration of oral secretions laden with pathogens (the dirty mouth) may lead to pneumonia particularly in the immunocompromised and may be reduced by meticulous attention to oral hygiene among other measures (Sjögren et al., 2008).

Recent experimental work provides a salutary lesson in the importance of the content of the aspirate. Many patients with dysphagia are given thickened liquids to increase liquid viscosity and to reduce bolus speed and this is presumed to improve swallow safety (Lazenby Paterson, 2020). However, in animal models, recurrent aspiration of even small amounts of water thickened with commercially available thickeners result in significant pulmonary inflammation and aspiration of larger amounts of thickened water results in lung oedema and death (Natiz-Zeltzer et al., 2018, 2020). 
Table 1

Determinants of pneumonia in dysphagia

\begin{tabular}{lll}
\hline Volume, frequency and content of aspiration & Anterograde & $\begin{array}{l}\text { Nasopharyngeal secretions } \\
\text { Food and fluid } \\
\text { Vomitus }\end{array}$ \\
& Retrograde & $\begin{array}{l}\text { Gastro-oesophageal reflux } \\
\text { Tube feeding }\end{array}$ \\
& & Mouth cleanliness/ oropharyngeal colonisation \\
Bacterial content of aspirate & Cough reflex & Level of consciousness \\
Patient defences & Mucociliary clearance & Lung health (e.g. chronic obstructive pulmonary disease) \\
& Immune response & \\
& General health/ frailty & \\
\hline
\end{tabular}

\subsection{Aspiration and pneumonia?}

Aspiration is not synonymous with pneumonia or with 'aspiration pneumonia'. The latter has been described as "An ambiguous term used for a diagnosis of uncertainty" (Ferguson et al., 2008). Dysphagia is one but not the strongest risk factor for pneumonia in frail older people (Langmore et al., 2002). Pneumonia is ultimately caused by pathogenic microorganisms causing infection in a vulnerable host (Marik, 2011) (Table 1). People with dysphagia aspirate more than food or fluid. The material that may enter the airways includes saliva and mucus from the nose, throat, and sinuses which, if colonised by pathogenic bacteria, may result in infection in a vulnerable person. Modifying food texture, thickening liquids, feeding tubes or keeping a person nil by mouth cannot prevent aspiration of oropharyngeal secretions or gastric contents; indeed, feeding tubes can increase the risk of aspiration (Gomes et al., 2015; American Geriatrics Society Ethics Committee, 2014).

\subsection{Aspiration and the RCP guidance}

The RCP guidance warns (in words taken almost verbatim from our previous paper (Murray et al., 2019)) against "common misperceptions that there is a straightforward relationship between aspiration and pneumonia and that interventions like nil by mouth or CANH [clinically assisted nutrition and hydration] will reduce the risks..." (RCP, 2021, pp. 25-26). This is indeed a common misperception (Askren \& Leslie, 2019), but one that this guidance may inadvertently reinforce as some of the recommendations (and the need for such guidance) make no sense unless it is presumed that aspiration causes serious adverse pulmonary events. For example, it is noted that a risk of aspiration and failure to "comply with texture modification" will trigger the need for a "formal MDT meeting ... at which the risks of aspiration are discussed" (RCP, 2021, pp. 63-65) and that "Advance care planning and treatment escalation plans should be reviewed in line with the 'risk feeding' decision" (RCP, 2021, pp. 25-26).

The guidance also notes: "Aspiration pneumonia can occur with both gastrostomy and NGT [nasogastric tube] feeding, although there is a danger that pneumonia may be ascribed to aspiration of feed when in fact the patient has developed nosocomial pneumonia because of their frailty and respiratory muscle weakness" (RCP, 2021, p. 40). This statement accurately reflects how difficult it is to distinguish troublesome dysphagia related events from other possible causes of chest infections. For aspiration to be feared, acknowledged, discussed at MDT meetings and trigger reviews of treatment escalation plans we should have a high degree of certainty - which is often lacking - that this is the cause that needs addressing.

\section{7. "Unsafe to swallow"}

The guidance refers to those with "unsafe oral intake", who are "unsafe to swallow" and to a "very high risk of aspiration' triggering the need for MDT meetings and even the need for legal advice. What do these terms mean and can they be accurately identified? Elsewhere, it is correctly stated that " $[a] n$ attempt to categorise someone's abilities on a continuum is always arbitrary" and that swallowing abilities fluctuate with time, fatigue and situational factors (RCP, 2021, pp. 19-20). Defining a person's swallowing ability as 'unsafe' or high risk' is indeed arbitrary as well as assessor-dependent. It is noted in the guidance that those performing swallow assessments will often err on the side of caution when considering swallowing to be unsafe (RCP, 2021, pp. 63-65). 
Judgements regarding safety and risk of aspiration are usually based, in hospital practice at least, on an instrumental assessment such as a video-fluoroscopic swallowing study (VFSS). However, the test-retest reliability of these assessments is unclear (Groher \& Groher, 2011) and inter-rater and intra-rater reliability of judgements can be poor even with experienced raters (Baijens et al., 2013). Also, 'unsafe swallows' are commonly found when VFSS is performed in healthy people (Butler et al., 2018).

There is limited evidence that the greater the degree of aspiration on a VFSS the greater the subsequent risk of adverse pulmonary events such as pneumonia and pneumonitis (Steele \& Grace-Martin, 2017). However, a large retrospective study of patients with documented aspiration on VFSS found no difference, over a 54-month follow-up period, in the time to first pulmonary event (pneumonia, pneumonitis or other life-threatening pulmonary infection) or survival between those allocated to different treatment options including modified texture diets and nil by mouth status (Bock et al., 2017). The authors concluded:

"Our data would suggest that severity of aspiration... has no significant effect on overall mortality. Altering diets to restrictive consistencies or even NPO [NBM] status has a profound effect on patient quality of life. Our data would suggest that these prohibitions may have minimal effect on the natural clinical course of the dysphagia patient".

\section{Do swallow interventions prevent adverse pulmonary events?}

The anxiety of professionals when patients do not follow their recommendations especially regarding modified texture diets reflects a widespread belief that such interventions work and can prevent pneumonia (McCurtin \& Healy, 2017). However, multiple systematic reviews have concluded that there is no convincing evidence that these interventions prevent pneumonia and its consequences in those with dysphagia (Beck et al., 2017; Hines et al., 2010; Painter et al., 2017; Speyer et al., 2010). Feeding tubes and some dietary consistencies may increase the risk of severe pneumonia (Gomes et al., 2015; Finucane et al., 1999; Robbins et al., 2008).

We, and others, have commented on the disconnect between the limited evidence base and the beliefs and practices of many professionals and the consequent overrestriction of diets and overuse of interventions like thickened liquids and texture modified foods (Lazenby-Paterson, 2020; O'Keeffe, 2018; McCurtin \& Clifford, 2015; Groher \& McKaig, 1995). As the authors of a recent textbook on dysphagia noted: 'Simply stated, we have no strong guidelines to "match" a diet level or degree of thickened liquid to a patient based on clinical or imaging studies as currently engaged' (Groher \& Crary, 2020).

\section{Where do the $\mathrm{RCP}$ recommendations apply?}

It is implied (although never stated explicitly) that the RCP recommendations regarding risk feeding apply in situations, such as in hospitals or residential care facilities, where carers and professionals effectively can or do exert complete control over the production, presentation and, perhaps particularly, the administration of food or fluid. How relevant are the recommendations if, for example, a person can shop or cook for him or herself or can order and eat a takeaway meal?

\section{Role of multidisciplinary team meetings}

The term 'multidisciplinary team' (MDT) in healthcare can describe a variety of different interprofessional working arrangements (Øvretveit, 1996). MDT meetings where a variety of relevant disciplines share their expertise and perspective are common and helpful in hospital and rehabilitation settings. There is a strong emphasis in the RCP guidance on "mandatory" "formal" MDT meetings and the concerns of "the team". This raises a number of issues.

- Most healthcare decisions, including those regarding oral intake, involve individual professionals accepting personal responsibility to communicate the pros and cons of different options to a patient and recording the patient's informed choice. MDT decision making and recommendations always entails a risk that because everybody is responsible, nobody is responsible.

- As well as different disciplines, MDTs are comprised of individuals who will differ in seniority, experience and risk tolerance. The requirement that legal advice might should be needed in some circumstances sought if the risks of oral feeding "cannot be mitigated to a degree sufficient to satisfy the concerns of the team as a whole" 
(our emphasis) (RCP, 2021, pp. 25-26) would place decision making at the mercy of the most risk averse member of the team.

- We previously suggested that because many people's swallowing abilities and preferences fluctuate "staff need to have, and be encouraged to use, common sense, flexibility and judgement in these circumstances" (Murray et al., 2019). The policy qualifies that by stating that: "Suitably skilled staff should be encouraged to use common sense, flexibility and judgement..." (RCP, 2021, pp. 25-26). What 'suitably skilled' means is not defined and could be interpreted as limited to SLTs. Also, it is difficult to see how staff could feel much freedom to vary from the documented recommendation of the MDT if, for example, someone who had agreed to take thickened liquids asks for ordinary clear fluids to alleviate thirst on a hot summer's day. Staff members are, we suggest, more likely to refuse that person thin fluids or to seek that another MDT meeting be convened so see if that can be 'allowed'.

- What is to occur in residential care facilities (or even in someone's own home) if somebody is observed to have some difficulties eating and drinking? In the acute hospital a mandatory MDT meeting would be required if they were to continue to eat and drink, but many residential care facilities will not have ready access to an SLT, let alone a full MDT. This seems a recipe for prolonged periods of nil by mouth which is what risk feeding policies purport to avoid - while referrals are made, and assessments arranged.

There is a sense in which the desire for MDT involvement is understandable. If you have labelled the swallow as unsafe and the person as at high risk for aspiration, (even if, as we have argued earlier, the grounds for these designations are unreliable) you or perhaps the choice of terminology - have, in effect, made a rod for your own back. How can you recommend oral intake after saying that it's a dangerous choice? Perhaps only if you have the comfort of other professionals backing you up!

\section{Legal aspects of risk feeding}

About half of the section on risk feeding in the RCP guidance relates to the law, liability and legal advice in different situations It is, of course, reasonable that a healthcare policy should take account of particularly complex cases. It is also obviously important that practitioners in England and Wales have an adequate understanding of the Mental Capacity Act 2005. Nevertheless, the legal emphasis is surprising, and informative. It reinforces to staff that they are right to be nervous if people with swallowing problems are 'allowed' to eat and drink. The message to patients is: if you make a choice to continue to eat and drink in a way contrary to our advice, then that decision, even if it is yours to make because you have capacity to decide, is unwise, and we need to be clear - for our own protection from legal liability - that you understand the risks of not following our advice.

This is not a message to be given lightly: it suggests a high degree of certainty about what is best for the person. It might be justified, for example, if recommending cutting up food for someone at high risk for choking but, as we have shown earlier, cannot be justified on current evidence if the propose of modifying diets is to prevent death from aspiration and pneumonia.

\subsection{Need for clarity regarding situations where legal advice should be sought}

The most striking statement is: "If (1) the risks of the relevant route cannot be mitigated to a degree sufficient to satisfy the concerns of the team as a whole; and (2) the patient still wishes only to receive nutrition and hydration by that route, then legal advice should be sought as to whether a court application is required, for instance that a declaration that the team are not under a duty to provide nutrition and hydration in the fashion chosen by the person, even if the end result is their death" (RCP, 2021, pp. 25-26).

Apart from the odd choice of words ("relevant route" when only oral intake seems applicable), it is unclear when such an extraordinary step might be taken. Some taxonomy should surely be provided of situations that would justify the extreme course of going to court to say, in effect, this person (who has capacity to decide for him or herself) wants to eat and drink in a way that might lead to their death and we want your permission not to facilitate this even if our action leads to their death.

It is important to distinguish between asphyxiation and other potential side effects from eating and drinking. If staff are responsible for feeding someone who is at high risk of choking to death, they would be perfectly entitled to say: 'No. I won't administer food of 
a size or at a speed that will clearly be dangerous for you. I will cut up that large piece of steak and only give you the next piece when you've swallowed this one'. To do otherwise would be reckless and potentially homicidal feeding rather than just risk feeding. If legal advice or court orders are needed to back up such common-sense measures in this scenario, so be it. However, we do not see any justification for extrapolating from this type of situation to one where the concern is that the person might get pneumonia due to aspiration.

\subsection{Dignity and safety of carers}

The recommendations state that the suggested approach reflects the fact that "the law does not require those involved to be placed in situations that they conscientiously consider either undignified or dangerous" and that "[i]n any 'risk feeding' decision, there needs to be a calibration between being risk averse, and placing carers in an impossible position in the name of patient autonomy" (RCP, 2021, pp. 25-26). This is an odd, almost resentful dichotomy. What situations or impossible position? What are the dangers?

The legal case quoted in support of this approach involved a dispute about whether relatives of someone with severe disability could insist that carers undertake hazardous lifts, that is, lifts involving a real danger of injury to carers ( $A \& O R S, 2003$ ). The judgement, while noting that health and safety law does not require a guarantee of absolute safety of employees, acknowledged that healthcare workers are entitled to have their health, safety and dignity respected and that sometimes a balancing exercise may be required between competing rights of workers and clients.

The judgement also noted that "context is everything". It is hard to see any dangers in feeding for staff analogous to those involved in manual handling. In the policy, does "unacceptable coughing and choking" mean unacceptable to carers and so engage their dignity rights (RCP, 2021, p. 20)? It is certainly distressing for anyone to see, for example, someone who is coughing severely while drinking water. However, one's even greater sympathy in the circumstance must be with the person who is so desperate to alleviate thirst that this outweighs the distress caused by fluid going down the wrong way. It is difficult to see how any balancing exercise in these circumstances would favour a carer.

\subsection{Legal professionals need accurate and balanced information}

Legal advisors and judges do not themselves have healthcare expertise. If lawyers and courts are told by healthcare professionals that someone has an unsafe, high-risk swallow, they are likely to interpret this as a 'dangerous swallow' - where the person risks death with every mouthful - and will make their recommendations and judgements accordingly. Unless these legal professionals are clearly informed, they will not be aware that swallow determinations often err on the side of caution, or of questions over the validity of these designations and of how predictive they are of adverse events (Bock et al., 2017) and of the lack of evidence that the 'safer' recommendations actually work (O’Keeffe, 2018).

\section{Risk feeding policies and defensive medicine}

\begin{abstract}
"A swallow assessment can be difficult to perform and will often err on the side of considering swallowing to be unsafe. Once a decision for a patient to be 'nil by mouth' is made it may be difficult for clinicians or family to override it" (RCP, 2021, pp. 63-65).
\end{abstract}

Risk feeding policies, and provisions such as mandatory MDT meetings and concerns about when to seek legal advice and about the rights of carers, make sense if the real underlying concern - the danger - is not so much that the patient will have an adverse outcome, but that staff will blame themselves and be criticised for that outcome. Unfortunately, this may indeed be the case.

As Levenson and Walker have noted regarding current practice, swallowing interventions "are commonly influenced by myths, misconceptions, fear, and cognitive biases" (Levenson \& Walker, 2019). The belief that aspiration is inextricably linked to pneumonia is deeply embedded among practitioners including SLTs (Askren \& Leslie, 2019). Many care home residents and others are on unnecessarily restrictive diets for this reason (Groher \& McKaig, 1995; McCurtin \& Clifford, 2015). It may also lead to staff taking on an unnecessary burden of guilt and responsibility if somebody with dysphagia does develop pneumonia, as is often inevitable. Such a pneumonia will often attract the poorly defined and often misleading label of 'aspiration pneumonia' 
(Ferguson et al., 2018). Staff may fear that they may be criticised by their colleagues, regulators or the person's relatives, or sued, for having 'allowed' infection to occur (Levenson \& Walker, 2019).

Much current practise in dysphagia care and the focus on preventing aspiration, rather than optimising hydration, nutrition and pleasure, is not justified by the evidence (Lazenby-Paterson, 2020; O'Keeffe, 2018; McCurtin \& Clifford, 2015). The occurrence of aspiration or pneumonia in those with dysphagia is unfortunately sometimes seen as an avoidable adverse event or evidence of poor care. While it is understandable that staff may be concerned about criticism in these circumstances, it is not right that patients should suffer because of such misconceptions. What is needed is better education about the limitations and lack of evidence regarding interventions such as modification of food and liquids, rather than risk feeding policies that may perpetuate unwarranted fears (Murray et al., 2019).

\section{Conclusions and recommendations}

The RCP guidance on risk feeding is likely to be influential and may be interpreted as an 'official' standard of care and encourage even more widespread adoption of risk feeding policies. We argue that the premises of the recommendations - in particular the lack of clarity regarding the nature, frequency and severity of different risks and the undue emphasis on aspiration as a risk and a potential cause of pneumonia - are flawed and that the guidance promotes an unduly defensive approach to oral intake.

Our view is that recommendations and decisions regarding eating and drinking when somebody has difficulty doing so should be viewed through the lens of evidence-based practice and informed consent rather than one of risk management and risk anxiety. People should be given information about their various options by healthcare professionals. After consideration of the pros and cons of the options in the context of their own goals and preferences, patients can make a decision which should then be respected. The information provided must be accurate and balanced, and the recommendations should acknowledge and reflect the uncertainty and lack of evidence associated with most interventions and practices in this patient group.

It is noted in the guidance that risk feeding may occur in situations such as "when someone with capacity makes a decision to eat and drink despite the risk; where CANH is not appropriate or declined; and where the benefits of eating and drinking orally (such as enjoyment and enhanced quality of life) are deemed to outweigh the risks (such as chest infections or choking)" (RCP, 2021, p. 24).

These essentially represent 'ordinary' decisionmaking. Take the example of where CANH is declined or is inappropriate. People need nutrition and hydration and in these circumstances the die is cast in favour of eating and drinking. Of course, there may be practical difficulties in maximising the oral intake of some such patients while minimising any discomfort, and the skills and advice of professionals will be helpful. However, practically challenging is not the same as ethically challenging and the risk feeding label is not helpful in these circumstances.

There is a need to 'dial back' the rhetoric with regard to swallow assessment management. We suggest that terms like 'unsafe swallow' and 'failing a swallow assessment' should be avoided. Similarly, it should be accepted that the risks of not eating and drinking are as important as those associated with eating and drinking. Adverse outcomes will occur in any healthcare setting. Many people are, for example, at risk for falls but we do not use a special risk-walking terminology or policy. People taking medication will sometimes have serious adverse outcomes. This is unfortunate but often unavoidable, and there is no reason for professionals who have adequately discussed the pros and cons of that medication to feel guilty about the outcome.

We accept that there are significant staff anxieties regarding people who eat and drink despite difficulties. However, many of the concerns are founded upon misperceptions regarding the relationship between aspiration and pneumonia or regarding the effectiveness of intervention. Education rather than policies that perpetuate such misconceptions is needed.

\section{Acknowledgments}

The authors have no acknowledgments.

\section{Conflict of interest}

The authors have no conflict of interest to report.

Given his role as an Editorial Board Member, Shaun T O'Keeffe had no involvement nor access to information regarding the peer review of this article. 


\section{References}

American Geriatrics Society Ethics Committee and Clinical Practice and Models of Care Committee, 2014. American Geriatrics Society feeding tubes in advanced dementia position statement. Journal of the American Geriatrics Society, 62(8), 15901593.

Askren, A., \& Leslie, P. (2019). Complexity of clinical decision making: Consent, capacity, and ethics. Seminars in Speech and Language, 40(3), 162-169. https://doi.org/10.1055/s-00391688838

Baijens, L., Barikroo, A., \& Pilz, W., 2013. Intrarater and interrater reliability for measurements in videofluoroscopy of swallowing. European Journal of Radiology, 82(10), 1683-1695. https://doi.org/10.1016/j.ejrad.2013.05.009

Beck, A.M., Kjaersgaard, A., Hansen, T., \& Poulsen, I. (2018). Systematic review and evidence based recommendations on texture modified foods and thickened liquids for adults (above 17 years) with oropharyngeal dysphagia-An updated clinical guideline. Clinical Nutrition, 37(6), 1980-1991. https:// doi.org/10.1016/j.clnu.2017.09.002

Bock, J.M., Varadarajan, V., Brawley, M.C., \& Blumin, J.H. (2017). Evaluation of the natural history of patients who aspirate. Laryngoscope, 127(Suppl 8), S1-S10. https://doi.org/ 10.1002/lary.26854

Butler, S.G., Clark, H., Baginski, S.G., Todd, J.T., Lintzenich, C., \& Leng, X. (2014). Computed tomography pulmonary findings in healthy older adult aspirators versus nonaspirators. The Laryngoscope, 124(2), 494-497. https://doi.org/10.1002/lary.24284

Butler, S.G., Stuart, A., Markley, L., Feng, X., \& Kritchevsky, S.B. (2018). Aspiration as a function of age, sex, liquid type, bolus volume, and bolus delivery across the healthy adult life span. Annals of Otology, Rhinology \& Laryngology, 127(1), 21-32. https://doi.org/10.1177/0003489417742161

Office for National Statistics (ONS). (2018). Choking related deaths registered in England and Wales, 2014 to 2017. (009342). Office for National Statistics. Retrieved August 8, 2021, from https://www.ons.gov.uk/peoplepopulationand community/birthsdeathsandmarriages/deaths/adhocs/009342 chokingrelateddeathsregisteredinenglandandwales2014to2017

Ekberg, O., \& Feinberg, M. (1992). Clinical and demographic data in 75 patients with near-fatal choking episodes. Dysphagia, 7(4), 205-208. https://doi.org/10.1007/BF02493471

Elflein, J. (2021). Number of deaths due to choking in the United States from 1945 to 2019. Statista. Retrieved August 8, 2021, from https://www.statista.com/statistics/527321/deathsdue-to-choking-in-the-us/

Ferguson, J., Ravert, B., \& Gailey, M. (2018). Aspiration: /aspə'rāSH(ə)n/: Noun: An Ambiguous Term Used for a Diagnosis of Uncertainty. Clinical Pulmonary Medicine, 25(5), 177-183. https://doi.org/10.1097/cpm.0000000000000277

Finucane, T.E., Christmas, C., \& Travis, K. (1999). Tube feeding in patients with advanced dementia: a review of the evidence. JAMA, 282(14), 1365-1370. https://doi.org/10.1001/jama.282. 14.1365

Gomes, C.A., Jr., Andriolo, R.B., Bennett, C., Lustosa, S.A., Matos, D., Waisberg, D.R., \& Waisberg, J. (2015). Percutaneous endoscopic gastrostomy versus nasogastric tube feeding for adults with swallowing disturbances. Cochrane Database Syst Rev, 5, CD008096. https://doi.org/10.1002/14651858. CD008096.pub4
Groher, M.E., \& Crary, M.A. (2020). Dysphagia-E-Book: Clinical Management in Adults and Children. Elsevier Health Science.

Groher, M.E., \& Groher, T.P., 2012. When safe oral feeding is threatened: End-of-life options and decisions. Topics in Language Disorders, 32(2), 149-167. https://doi.org/10.1097/ TLD.0b013e3182543547

Groher, M.E., \& McKaig, T.N. (1995). Dysphagia and dietary levels in skilled nursing facilities. $J$ Am Geriatr Soc, 43(5), 528-532. https://doi.org/10.1111/j.1532-5415.1995. tb06100.x

Hansjee, D. (2018). An Acute Model of Care to Guide Eating \& Drinking Decisions in the Frail Elderly with Dementia and Dysphagia. Geriatrics (Basel), 3(4). https://doi.org/10.3390/ geriatrics3040065

Hines, S., McCrow, J., Abbey, J., \& Gledhill, S. (2010). Thickened fluids for people with dementia in residential aged care facilities. International Journal of Evidence-Based Healthcare, 8(4), 252-255. https://doi.org/10.1111/j.1744-1609.2010. 00188.x

Langmore, S.E., Skarupski, K.A., Park, P.S., \& Fries, B.E. (2002). Predictors of aspiration pneumonia in nursing home residents. Dysphagia, 17(4), 298-307. https://doi.org/10.1007/s00455002-0072-5

Lazenby-Paterson, T. (2020). Thickened liquids: do they still have a place in the dysphagia toolkit? Curr Opin Otolaryngol Head Neck Surg, 28(3), 145-154. https://doi.org/10.1097/MOO.000 0000000000622

Levenson, S.A., \& Walker, V.L. (2019). It is time to revamp approaches to managing dysphagia in nursing homes. Journal of the American Medical Directors Association, 20(8), 952-955. https://doi.org/10.1016/j.jamda.2019.06.005

Marik, P.E. (2011). Pulmonary aspiration syndromes. Current opinion in Pulmonary Medicine, 17(3), 148-154. https://doi. org/10.1097/MCP.0b013e32834397d6

McCurtin, A., \& Clifford, A.M. (2015). What are the primary influences on treatment decisions? How does this reflect on evidence-based practice? Indications from the discipline of speech and language therapy. Journal of Evaluation in Clinical Practice, 21(6), 1178-1189. https://doi.org/10.1111/jep.12385

McCurtin, A., \& Healy, C. (2017). Why do clinicians choose the therapies and techniques they do? Exploring clinical decision-making via treatment selections in dysphagia practice. International Journal of Speech-Language Pathology, 19(1), 69-76.

Murray, A., Mulkerrin, S., \& O'Keeffe, S.T. (2019). The perils of 'risk feeding'. Age Ageing, 48(4), 478-481. https://doi.org/ 10.1093/ageing/afz027

Nativ-Zeltzer, N., Kuhn, M.A., Imai, D.M., Traslavina, R.P., Domer, A.S., Litts, J.K., Adams, B., \& Belafsky, P.C. (2018). The effects of aspirated thickened water on survival and pulmonary injury in a rabbit model. Laryngoscope, 128(2), 327-331. https://doi.org/10.1002/lary.26698

Nativ-Zeltzer, N., Ueha, R., Nachalon, Y., Ma, B., Pastenkos, G., Swackhamer, C., Bornhorst, G.M., Lefton-Greif, M.A., Anderson, J.D., \& Belafsky, P.C. (2021). Inflammatory Effects of Thickened Water on the Lungs in a Murine Model of Recurrent Aspiration. Laryngoscope, 131(6), 1223-1228. https://doi.org/ 10.1002/lary.28948

Norfolk and Norwich University Hospital (NNUH). (2021). Management of Risk Feeding v3. Norfolk and Norwich University Hospital. https://www.nnuh.nhs.uk/publication/managementof-risk-feeding-v3/ 
O'Keeffe, S.T. (2018). Use of modified diets to prevent aspiration in oropharyngeal dysphagia: is current practice justified? BMC Geriatrics, 18(1), 167. https://doi.org/10.1186/s12877018-0839-7

$A \&$ ORS, $R$ (On the application of) $V$ East Sussex County Council \& ANOR, EWHC (2003). Casemine. Retrieved August 8, 2021, from https://www.casemine.com/judgement/uk/ $5 \mathrm{a} 8 \mathrm{ff} 76760 \mathrm{~d} 03 \mathrm{e} 7 \mathrm{f} 57 \mathrm{eac} 2 \mathrm{dd}$

Øvretveit, J. (1996). Five ways to describe a multidisciplinary team. Journal of Interprofessional Care, 10(2), 163-171. https://doi.org/10.3109/13561829609034099

Painter, V., Le Couteur, D.G., \& Waite, L.M., 2017. Texturemodified food and fluids in dementia and residential aged care facilities. Clinical Interventions in Aging, 12, 1193. https:// doi.org/10.2147/CIA.S140581

Royal College of Physicians (RCP). (2021). Supporting people who have eating and drinking difficulties. A guide to practical care and clinical assistance, particularly towards the end of life. Royal College of Physicians. Retrieved August 8, 2021, from https://www.rcplondon.ac.uk/projects/outputs/ supporting-people-who-have-eating-and-drinking-difficulties

Robbins, J., Gensler, G., Hind, J., Logemann, J.A., Lindblad, A.S., Brandt, D., Baum, H., Lilienfeld, D., Kosek, S., Lundy, D., Dikeman, K., Kazandjian, M., Gramigna, G.D., McGarveyToler, S., \& Miller Gardner, P.J. (2008). Comparison of 2 interventions for liquid aspiration on pneumonia incidence: a randomized trial. Annals Internal Medicine, 148(7), 509-518. https://doi.org/10.7326/0003-4819-148-7-200804010-00007

Rosenbek, J.C., Robbins, J.A., Roecker, E.B., Coyle, J.L., \& Wood, J.L. (1996). A penetration-aspiration scale. Dysphagia, 11(2), 93-98. https://doi.org/10.1007/BF00417897

Sommerville, P., Lang, A., Harbert, L., Archer, S., Nightingale, S., \& Birns, J. (2017). Improving the care of patients feeding at risk using a novel care bundle. Future Healthcare Journal, 4(3), 202-206. https://doi.org/10.7861/futurehosp.4-3-202

Speyer, R., Baijens, L., Heijnen, M., \& Zwijnenberg, I. (2010). Effects of therapy in oropharyngeal dysphagia by speech and language therapists: a systematic review. Dysphagia, 25(1), 40-65. https://doi.org/10.1007/s00455-009-9239-7
Steele, C.M., Alsanei, W.A., Ayanikalath, S., Barbon, C.E., Chen, J., Cichero, J.A., Coutts, K., Dantas, R.O., Duivestein, J., Giosa, L., Hanson, B., Lam, P., Lecko, C., Leigh, C., Nagy, A., Namasivayam, A.M., Nascimento, W.V., Odendaal, I., Smith, C.H., \& Wang, H. (2015). The influence of food texture and liquid consistency modification on swallowing physiology and function: a systematic review. Dysphagia, 30(1), 2-26. https:// doi.org/10.1007/s00455-014-9578-x

Sjögren, P., Nilsson, E., Forsell, M., Johansson, O., \& Hoogstraate, J. (2008). A systematic review of the preventive effect of oral hygiene on pneumonia and respiratory tract infection in elderly people in hospitals and nursing homes: effect estimates and methodological quality of randomized controlled trials. Journal of the American Geriatrics Society, 56(11), 2124-2130. https://doi.org/10.1111/j.1532-5415.2008.01926.x

Steele, C.M., \& Grace-Martin, K. (2017). Reflections on Clinical and Statistical Use of the Penetration-Aspiration Scale. Dysphagia, 32(5), 601-616. https://doi.org/10.1007/s00455017-9809-z

Swan, K., Speyer, R., Heijnen, B.J., Wagg, B., \& Cordier, R. (2015). Living with oropharyngeal dysphagia: effects of bolus modification on health-related quality of life-a systematic review. Quality of Life Research, 24(10), 2447-2456. https:// doi.org/10.1007/s11136-015-0990-y

Wirth, R., Dziewas, R., Beck, A.M., Clave, P., Hamdy, S., Heppner, H.J., Langmore, S., Leischker, A.H., Martino, R., Pluschinski, P., Rosler, A., Shaker, R., Warnecke, T., Sieber, C.C., \& Volkert, D. (2016). Oropharyngeal dysphagia in older persons from pathophysiology to adequate intervention: a review and summary of an international expert meeting. Clinical Interventions in Aging, 11, 189-208. https://doi.org/10.2147/CIA. S97481

Wu, W.S., Sung, K.C., Cheng, T.J., \& Lu, T.H. (2015). Associations between chronic diseases and choking deaths among older adults in the USA: a cross-sectional study using multiple cause mortality data from 2009 to 2013. BMJ Open, 5(11), e009464. 